\title{
Volatility and fluctuations in preferences for Red, Yellow and Blue colours are indicators of personality traits and biological status
}

\author{
George John \\ Former Vice Chancellor, Birsa Agricultural University, Ranchi, India \\ Former Sr. Adviser, Department of Biotechnology, Government of India, Apartment : 5140, B 7, Vasant Kunj, New Delhi 110070, India
}

\section{A B S T R A C T}

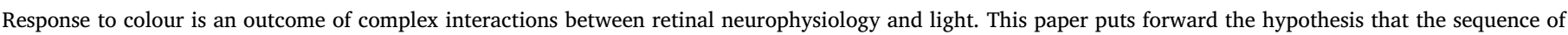

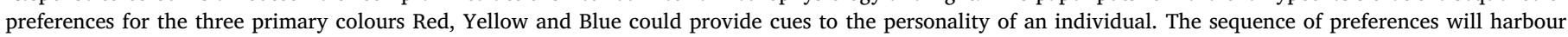

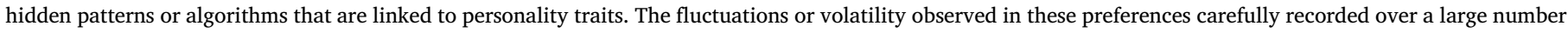

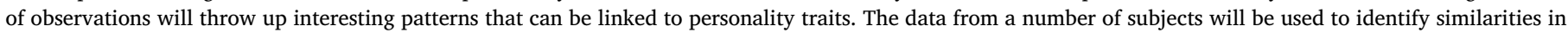

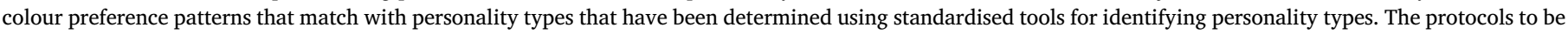

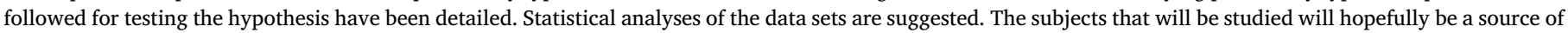

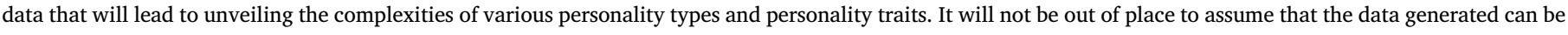
extrapolated to read the biological and physiological conditions also.

\section{Introduction}

Why do two colours, put one next to the other, sing ?-Pablo Picasso

As preposterous as it may seem, this paper puts forward with some audacity the proposition that preference for the primary colours Red, Yellow and Blue, and the underlying volatility in these preferences will reveal the personality types at one level; and also provide a window to the biological and physiological status of an individual. This can reveal information at various levels such as the present health, and susceptibility to and likelihood of a range of ailments. Consequentially, this can be extrapolated to map the health status and predict the life span of an individual. Since biological systems are guided by algorithms [1-5], their unravelling is expected to provide tools and information that can be used to predict lifespan with a fair degree of accuracy, and also identify the event that is likely to bring about the end.

This hypothesis has originated from the premise that human response to colour is triggered by deep seated 'biological impulses' that are manifested through various physiological cum psychological responses. A number of studies are available on colour preferences and substantial data has been generated to map personality types [6-10]. Many of these have centred around the use of various colours and colour groups to get a cue of the human personality and its underlying complexities. Families of different colours have been used for interpreting personality types but these have not met with complete success in unveiling personality types.
A more researched paper here might have standardised or toned down the statements; got concepts rounded off, leading to a rather conventional discourse. The radical approach of this paper is primarily because it is based on limited research, but on large surmises that went into its preparation, for constructing a hypothesis that from the beginning will require a 'Bayesian approach' and scientific scaffolding to be able to draw robust conclusions.

\section{Brief review of literature}

The basis of colour identification has been investigated by many researchers. It has remained a robust research topic. Studies conducted have largely focused on the mapping of predetermined colour preferences or existing choices. Colour preferences can be used to predict individual personality characteristics. A landmark study [11] laid the foundation for a deep understanding of the subject. Colour perception choices are quite strong and they are dependent on a number of underlying factors such as personality types [12,6,7,8,13,14], ethnic background of the subjects [15-18], age [19-24], gender [25-29], education [30], mental status and information processing in such conditions [31-33]. It has been seen that brain activity is modulated by colour preference which implies a correlation between colour preference and personality traits; and colour preference could be a pervasive aspect of visual processing [34]. Marketing strategies place a lot of importance on effects of colour and one interesting finding shows that colour results in instant subconscious judgement [35]. Ecological

E-mail address: gjohn@nic.in. 
valence theory of colour preferences proposes that human colour preferences arise from average affective responses to colour associated objects $[9,10]$. Preference for colours vary with variation in the hue of colours [36]. In short, considerable volume of literature is available on colour preferences of humans, and colour choice inventorisation is fairly extensive. Colour permeates every aspect of life and colour symbolism has been extensively used even in literature and poetry [37].

The basic structure of the retina has been described along with its intricate relationship with the neurological configuration [38-42]. The sequence of events starting from the falling of light on the eye, to the identification of colours or objects following a complex neurological processing in colour identification have been described by workers $[43,44,45,41]$. The molecular evolution of vision has been traced [46]. The specialized photoreceptors or cones detect light and also distinguish specific wavelengths of light or colours $[43,45,41,42]$. The protein opsin is a fundamental component of photopigment that plays the vital role of tuning colour photoreceptors to specific wavelengths of light ie; colour and provides a richer colour experience $[47,43]$. The complex neurophysiological mechanism underlying colour recognition is regulated by genes $[40,46]$ and gets altered by impairments [48] and disorders [31,32]. A functional neuropsychological system forms the basis of any personality trait and this is moulded by the combined effect of genes and environment [49].

\section{Existing gaps in knowledge}

Currently there seem to be no studies on colour preference of primary colours Red, Yellow and Blue, and the underlying volatility of preferences over a series of recordings. Though there are researches showing changes in colour preference due to seasonal variations, preferences linked to liked or disliked coloured objects, or differences within individuals from one time to another [50-53], spontaneity in colour choices [21,22], or a link between impulsiveness and chroma [54], there are no studies that observed changes in preferences over many successive recordings. This clearly underscores the need to capture the momentary changes, fluctuations or volatility in colour preferences if any with reference to the primary colours Red, Yellow and Blue, over a large number of observations, to unravel any underlying patterns that can be linked to personality types. Hence this hypothesis was conceived. The opinion of Karl J. Friston (personal communication, 2018) on the concept was that 'it may be an interesting way to phenotype the volatility of prior preferences ... and the way in which these fluctuations evolve over time should indeed reflect something about how constant prior beliefs or preferences are'.

It is surmised that human response to the primary colours Red, Yellow and Blue would be 'primeval' and hence reflective of the personality type to a greater extent than that with other colours. Arguably, the response to individual non primary colours or shades in a family of primary colours will be muted and overlapped in comparison to that for the primary colour itself, thereby reducing its readability ie; restricting the use of results for interpreting personality types.

\section{Hypothesis}

The hypothesis proposed is that the sequence of colour preferences for Red, Yellow and Blue will reveal patterns, fluctuations, waves or volatility that can be matched with personality types. The premise here is that the primary colours Red (R), Yellow (Y) and Blue (B) are the foundations on which colour preferences are determined. Our response to the colours Red, Yellow and Blue is a reflection of a 'primeval' urge or response. This gets 'muted' when the colours Red, Yellow and Blue are used along with the shades of the same colour or with shades of other colours. The primary colours Red, Yellow and Blue cannot be created from other colours but they are the base from which other colours can be created. Hence, unravelling and understanding the patterns and volatility in preferences for these three colours will provide a key to 'deep seated aspects' of the human personality and the same can be extrapolated to read the physiological or biological status that might be reflective even of health conditions.

It must be noted that the use of a 'family' of colours of a primary colour masks the response of the subject and therefore provides an inaccurate cue to a person or his personality type. Hence the proposition is that colour preferences should be ascertained only in response to the primary colours RYB arranged in any fixed manner. The shade and chroma of the primary colours used will be as determined by International standards. The choices will be recorded under the following two situations to test the hypothesis.

(i) The preference sought to be recorded here is one that is based on the 'impulse' of the subject ie; immediately on seeing the colour plate. It should not be a choice that is arrived at by weighing the possible options. It should also not be one where the choice is already made or predetermined ie; before the colour plate is shown. In other words, it should be a spontaneous choice ie one that is presumably from the 'sub conscious mind'. Spontaneity is the essence of the choice and the key element in this component of the study.

(ii) In the second approach, the choice sequences are recorded not on an impulse as in the above, but after the subject takes a few seconds to mull over the choice that he wants to indicate.

\section{Methods to test the hypothesis}

Each subject that will be selected will be healthy and free from neurological disorders. The subject will be briefed on the study and what is expected of him. He will then be asked to indicate a preference sequence for the colours when the filled colour circles of Red, Yellow and Blue (RYB) arranged on a colour plate are shown. The Red, Yellow and Blue colours used will be as per International Colour Standards and they will be on a white background. Before the test is started, the subject should be asked to look at a white screen for about $30 \mathrm{~s}$ to minimise or eliminate any colours that may persist from objects seen prior to the start of the experiment. The preference sequence indicated by a subject can be for instance as RYB, BYR, BRY etc using a fixed sequence shown to the subject.This will be repeated for about 500 times, preferably 1000 times and the preferences recorded manually or by using a device where the preference sequences are keyed in.

\section{(i) Recording 'impulse' based choice.}

It should be explained to the subject that the essential thing here is that the preference sequence indicated should be a spontaneous one and not one that is arrived at by mulling over various possibilities. The subject is required to indicate the sequence of preference immediately on seeing the colour plate and momentarily close his eyes before looking at the colour plate again for recording the next sequence of preferences.

A subject may have a liking for a particular colour, for example Blue colour, but indicating this as the first preference always is not a spontaneous response but expression of a predetermined choice. It should be a preference expressed on impulse ie; when the eye is opened to observe the colour plate. It is essential to instruct the subjects that they are required to indicate only their spontaneous preference. The study is designed to map the spontaneous preference arising on an impulse and not one that is based on a decision, since a decision made is an outcome that is arrived at by considering various possibilities. The key here is to record an impulse and not a considered decision. The cooperation of the subject is very important.

\section{(ii) Recording 'considered choice'}

A separate of set of experiments can be conducted where a subject is 


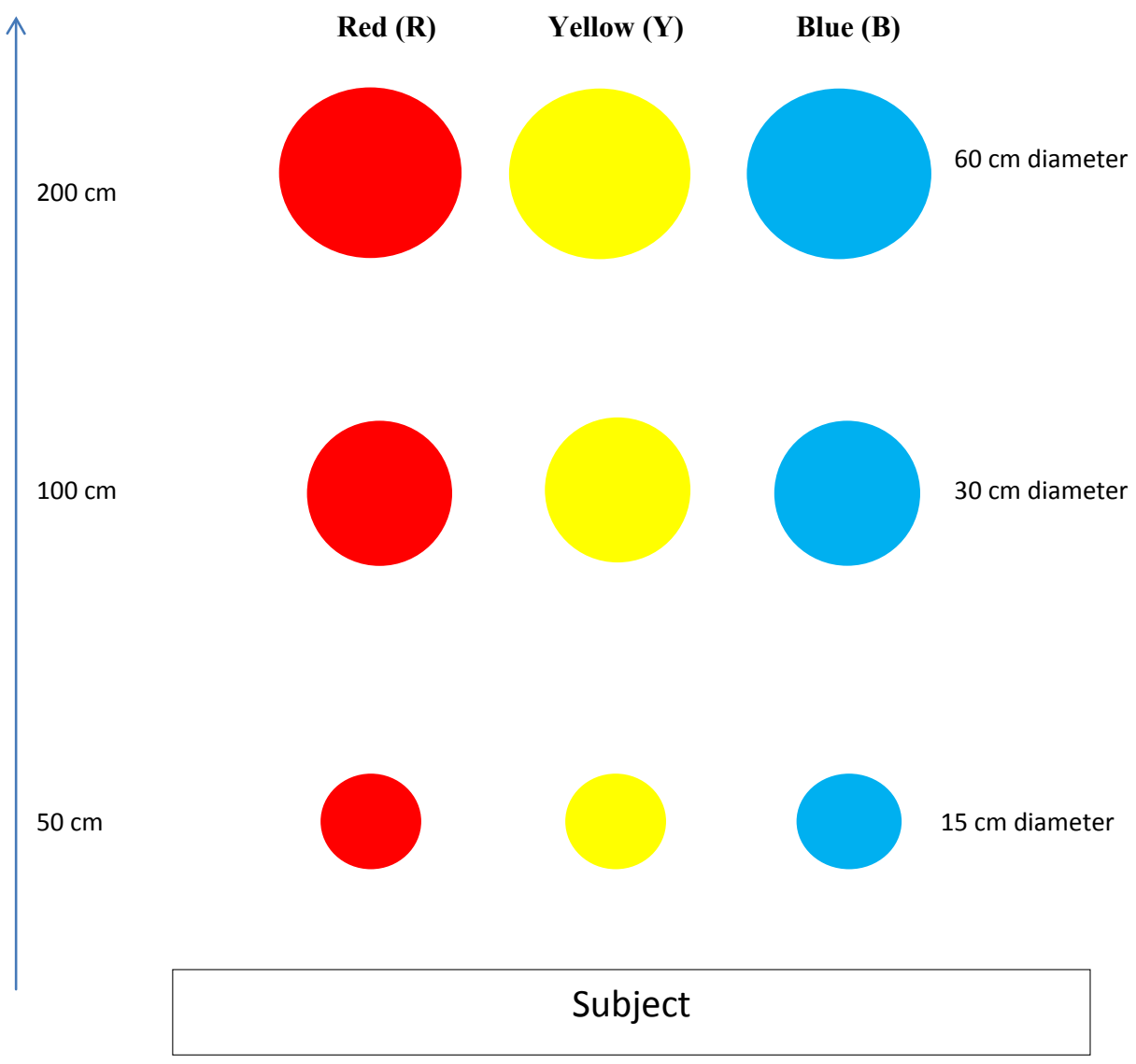

Fig. 1. Showing the distances from the subject and the corresponding sizes of colour circles for testing colour preference of Red (R), Yellow $(\mathrm{Y})$ and Blue (B). (Colours as per Internationally accepted standards for shades and chroma). (For interpretation of the references to colour in this figure legend, the reader is referred to the web version of this article.) allowed to indicate the order of preference after careful consideration of the RYB sequence on the colour plate. This method will record preferences that have been decided by the subject after a deliberation within himself. The preference exercised here is a reflection of prior preferences and inherent bias unlike the earlier set of recordings based on impulse. This data set will greatly enlarge the scope for testing the hypothesis proposed. The volatility patterns are likely to be different in both the cases.

\section{(iii) Notes}

The colour plate showing the three filled colour circles (with white background) can be of different sizes and placed at different distances as shown in Fig. 1. The shape chosen is a circle because it is presumably the least distracting shape. The colours RYB can be arranged in 6 permutation combinations (RYB,RBY,YBR,YRB,BRY,BYR). The distances/ size of colour circles provide 3 possibilities ie; a total of 18 combinations (Table 1). However the recording should be done only with one combination at a time since multiple combinations will clutter the input channel ie; give too many inputs to the brain that will require the brain to 'recalibrate' every time, thus impeding the flow of choices which is essential for identifying possible patterns. Also, about 500 non-stop recordings are considered a good database for drawing conclusions. It is also to be noted that if the recording does not proceed, say beyond 300 times, it cannot be continued subsequently for another 200 times after a time interval. In such cases they will have to be treated as two separate recordings, though falling short of the target. LED or LCD screens are not recommended. The recording room must be free of sounds and if necessary, ear plugs provided to the subjects so that inadvertent phenomena like 'colour hearing', not necessarily synaesthesia $[55,56]$ are avoided.

\section{Possible results and its implications}

The studies will generate considerable data and a fairly large number of colour preference sequences from many individuals that can be subjected to various statistical analyses. The statistical treatment will hopefully reveal colour preference patterns that can be linked to personality types of subjects. If validated and found linked/correlated to personality types, it would offer a simple tool for clinical research and to identify or 'read' personality types. The preference sequences recorded can be rearranged with a shifting of the last preference to the

Table 1

Colour sequences, distances and diameter of colour circles suggested for testing. (see Fig. 1 for schematic representation).

\begin{tabular}{|c|c|c|c|c|}
\hline \multirow{2}{*}{$\begin{array}{l}\text { Sl no } \\
1\end{array}$} & \multirow{2}{*}{$\begin{array}{l}\text { Colour sequence to be tested } \\
\text { RYB }\end{array}$} & \multicolumn{3}{|c|}{ Distance and diameter of the colour circles } \\
\hline & & $50 \mathrm{~cm} ; 15 \mathrm{~cm}$ & $100 \mathrm{~cm} ; 30 \mathrm{~cm}$ & $200 \mathrm{~cm} ; 60 \mathrm{~cm}$ \\
\hline 2 & RBY & $50 \mathrm{~cm} ; 15 \mathrm{~cm}$ & $100 \mathrm{~cm} ; 30 \mathrm{~cm}$ & $200 \mathrm{~cm} ; 60 \mathrm{~cm}$ \\
\hline 3 & YBR & $50 \mathrm{~cm} ; 15 \mathrm{~cm}$ & $100 \mathrm{~cm} ; 30 \mathrm{~cm}$ & $200 \mathrm{~cm} ; 60 \mathrm{~cm}$ \\
\hline 4 & YRB & $50 \mathrm{~cm} ; 15 \mathrm{~cm}$ & $100 \mathrm{~cm} ; 30 \mathrm{~cm}$ & $200 \mathrm{~cm} ; 60 \mathrm{~cm}$ \\
\hline 5 & BRY & $50 \mathrm{~cm} ; 15 \mathrm{~cm}$ & $100 \mathrm{~cm} ; 30 \mathrm{~cm}$ & $200 \mathrm{~cm} ; 60 \mathrm{~cm}$ \\
\hline 6 & BYR & $50 \mathrm{~cm} ; 15 \mathrm{~cm}$ & $100 \mathrm{~cm} ; 30 \mathrm{~cm}$ & $200 \mathrm{~cm} ; 60 \mathrm{~cm}$ \\
\hline
\end{tabular}

R (Red), Y (Yellow), B (Blue). (as per Internationally accepted standards for shades and chroma). 
Table 2

Recorded sequence and rearrangement that can be analysed.

\begin{tabular}{llll}
\hline Sl no & $\begin{array}{l}\text { Recorded } \\
\text { sequence } \\
\text { (sequence 1) }\end{array}$ & $\begin{array}{l}\text { Last colour shifted } \\
\text { to the first place } \\
\text { (sequence 2) }\end{array}$ & $\begin{array}{l}\text { Again last colour } \\
\text { shifted to first } \\
\text { place (sequence 3) }\end{array}$ \\
\hline 1 & RYB & BRY & YBR \\
2 & BYR & RBY & YRB \\
3 & RBY & YRB & BYR \\
4 & BRY & YBR & RYB \\
5 & BYR & RBY & YRB \\
6 & YBR & RYB & BRY \\
7 & YBR & RYB & BRY \\
8 & BRY & YBR & RYB \\
9 & BRY & YBR & RYB \\
10 (recordings to go & YRB & BYR & RBY \\
up to 500). & & &
\end{tabular}

R (Red), Y (Yellow), B (Blue). (as per Internationally accepted standards for shades and chroma).

first place, and in the next rearrangement, again the last one shifted to the first position (Table 2). Various other rearrangements can also be generated. In this manner the basic colour preference sequence can be used to generate sequence variants that can be subjected to further statistical analyses. It is purely speculative that this paradigm can be useful for testing preferences with three different shapes, three different words or any other parameter. It is conjectural that the colours RYB have a 'neurophysiological nexus' and preference sequences for this 'colour triplet' RYB will yield interesting patterns or become 'codons' of personality mapping.

\section{Statistical analysis}

The tests that could be used would depend on the nature of data and the sequences therein. Pearson Chi Square test and ANOVA can be considered. A Bayesian model is essential to construct the emerging conclusion and test its validity over a period of time. The usefulness of Apriori algorithm for analysis needs to be examined, perhaps after some data has been generated. Stochastic transitivity analysis can also be considered. Karl J.Friston (personal communication, 2018) opined that 'sequential entropy analysis could be applied to the patterns of choices to measure how stable or volatile they are and establish the construct validity of this entropy (or serial correlation) measure - in relation to other personality or psychology scores'.

\section{Conflict of interest}

There is no conflict of interest.

\section{Funding}

This work was not supported by any grant.

\section{Acknowledgement}

The author would like to thank Dr. Karl J. Friston, University College, London whose comments on the concept have been most invaluable and the writing of this paper was taken up at his suggestion. The author also thanks India International Centre, New Delhi, India for the library facilities.

\section{Appendix A. Supplementary data}

Supplementary data to this article can be found online at https:// doi.org/10.1016/j.mehy.2018.10.029.

\section{References}

[1] Navlakha S, Bar-Joseph Z. 2011. Algorithms in nature: the convergence of systems biology and computational thinking. Mol Syst Biol 7:546. EMBO and Macmillan Publishers Limited.

[2] Myers CL, Chiriac C, Troyanskaya OG. Discovering biological networks from diverse functional genomic data. Methods Mol Biol 2009;563:157-75.

[3] Nurse P. Life, logic and information. Nature 2008;454:424-6.

[4] Ward AJW, Herbert-Read JE, Sumpter DJT, et al. Fast and accurate decisions through collective vigilance in fish shoals. Proc Natl Acad Sci USA $2011 ; 108: 2312-5$

[5] Altintan D, Purutcuoglu V. Exact Stochastic Simulation Algorithms and Impulses in Biological Systems. Int J Comput Exp Sci Eng (IJCESEN) 2018;4(2):41-7.

[6] Cigic D, Bugarski V. Personality traits and colour preferences. Curr Top Neurol Psychiatr Relat Discip 2010;18(4):28-35

[7] Kabzinska K, Wieloch M, Filipiak D, et al. 2018. Profiling User's Personality Using Colours: Connecting BFI-44 Personality Traits and Plutchik's Wheel of Emotions. In book: Information Systems Architecture and Technology: Proceedings of 39th International Conference on Information Systems Architecture and Technology ISAT 2018.

[8] Ghorawat D, Madan R. Correlation between personality types and color shade preference. Int J Indian Psychol 2014;1(4):64-73.

[9] Palmer SE, Schloss KB. An ecological valence theory of human color preference. PNAS 2009;107(19):8877-82.

[10] Taylor C, Franklin A. The relationship between color-object associations and color preference: further investigation of ecological valence theory. Psychon Bull Rev 2012;19:190-7.

[11] Luscher M, Scott IA. The Luscher Color Test. Jonathan Cape Ltd. Great Britain.; 1970.

[12] Lange R, Rentfrow J. Color and personality: Strong's Interest Inventory and Cattell's 16PF. North Am J Psychol 2007;9:423-38.

[13] Rosenbloom T. Color preferences of high and low sensation seekers. Creativity Res J. 2006;18(2):233-9.

[14] Palmer SE, Schloss KB. 2015. Color Preference. Encyclopedia of Color Science and Technology. DOI:10.1007/978-3-642-27851-8_70-13. Springer Science Business Media.

[15] Dashti S, Izadan H, Mahyar F. 2013. A study of colour emotion for two colour combinations. In: 5th International Colour and Coatings Congress, December 2013 Ishfahan University of Technology, Iran.

[16] Rostami M, Izadan H, Mahyar F. Colour Emotion Models, CIELAB Colour Coordinates, and Iranian Emotional Responses. J Textiles Polymers 2015;3(2):46-54.

[17] Ou LC, Luo MR, Sun PL, et al. A cross-cultural comparison of colour emotion for two-colour combinations. Color Res Appl 2012;37(1):23-43.

[18] Gao XP, John H, Sato XT, et al. Analysis of Cross-Cultural Color Emotion. Color Res Appl 2007;32(3):223-9.

[19] Koleoso ON, Ehigie BO, Akhigbe KO. Colour Preference among Children in a Nigerian Montessori School. Mediterranean J Social Sci. 2014;5(1):325-32.

[20] Adams RJ. An evaluation of color preferences in early infancy. Infant Behav Dev 1987; 10:143-50.

[21] Zemach I, Chang S, Teller DY. Infant colour vision: Prediction of infants' spontaneous color preferences. Vision Res 2007;47:1368-81.

[22] Zemach IK, Teller DY. Infant color vision: Infants' spontaneous color preferences are well behaved. Vision Res 2007;47:1362-7.

[23] Beke L, Kutas G, Kwak Y, et al. Color preference of aged observers compared to young observers. Color Res Appl 2008;33:381-94.

[24] Franklin A, Bevis L, Ling Y, et al. Biological components of colour preference in infancy. Dev Sci. 2010;13:346-54.

[25] Bonnardel V, Lamming L. 2010.Gender differences in colour preference: personality and gender schemata factors. In: 2nd CIE Expert Symposium on Appearance, Ghent; September 8-10, 2010.

[26] Conway ML, Evans BJW, Evans JC, et al. Does Gender Influence Colour Choice in the Treatment of Visual Stress ? PLoS ONE 2016;11(9):e0163326https://doi.org/ 10.1371/journal.pone.0163326.

[27] Gelineau EP. A psychometric approach to the measurement of color preference. Percept Mot Skills 1981;53(1):163-74.

[28] Bonnardel V, Harper L, Duffie F, et al. Gender differences in colour preference: Men are more predictable than women. Perception 2006;35:187a.

[29] Hurlbert AC, Ling Y. Biological components of sex differences in color preference. Curr Biol 2007;17:623-5.

[30] Hanafy IM, Sanad R. Colour preferences according to educational background. Procedia - Social Behav Sci 2015;205:437-44.

[31] Tao B, Xu S, Pan X, et al. Personality trait correlates of color preference in schizophrenia. Transl Neurosci 2015;6:174-8.

[32] Fernandes TMP, Andrade SM, de Andrade MJO, et al. Colour discrimination thresholds in type 1 Bipolar Disorder: a pilot study. Nature Sci Rep 2017;7:16405.

[33] Yoon JH, Sheremata SL, Rokem A, et al. Windows to the soul: vision science as a tool for studying biological mechanisms of information processing deficits in schizophrenia. Front. Psychol. 2013;4:681.

[34] Racey C, Franklin A, Bird CM. 2018. The processing of color preference in the brain. bioRxiv preprint first posted online Jul. 3, 2018; http://dx.doi.org/10.1101/ 361006. doi: https://www.biorxiv.org/content/biorxiv/early/2018/07/03/ 361006.full.pdf. Accessed 1st Oct, 2018.

[35] Singh S. Impact of color on marketing. Manag Decis 2006;44(6):783-9.

[36] Hurlbert AC, Owen KA. Biological, cultural, and developmental influences on color 
preference. In: Elliott AJ, Fairchild MD, editors. Handbook of Color Psychology. Cambridge: Cambridge University Press; 2015. p. 454-80.

[37] Olesen J. Color Symbolism in Literature: What Do Colors Mean in Literature and Poetry? Accessed on 22 Sept 2018 https://www.color-meanings.com/colorsymbolism-in-literature-what-do-colors-mean-in-literature-and-poetry/; 2018.

[38] Braddick O, Atkinson J. Development of human visual function. Vision Res 2011;51:1588-609.

[39] Neitz J, Carroll J, Neitz M. Color Vision: Almost Reason Enough for Having Eyes. Optics \& Photonics News 2001;12(1):26-33.

[40] Nathans J, Thomas D, Hogness DS. Molecular genetics of human color vision: The genes encoding blue, green, and red pigments. Science 1986;232:193-202.

[41] Oyster CW. The Human Eye: Structure and Function. Sunderland, MA: Sinauer Associates, Inc.; 1999.

[42] Fernald RD. Evolution of eyes: Current Opinion in Neurobiology 2000;10:444-50

[43] King T. Human Color Perception, Cognition, and Culture: Why "Red" is Always Red. The Reporter- the window on imaging 2005;20(1):1-7.

[44] Livingstone MS, Hubel DH. Anatomy and physiology of a color system in the primate visual cortex. J Neurosci 1984;4(1):309-56.

[45] Wilson CG, Semenova EM, Hughes PM, et al. 2006. Eye structure and physiological functions. In: Touitou, Barry BW (eds.) Enhancement in Drug Delivery. CRC Press, pp. 473-487.

[46] Hunt DM. Molecular evolution of colour vision in primates. J Vision 2006;6(13). 34.
[47] Jameson KA, Highnote SM. Richer color experience in observers with multiple photopigment opsin genes. Psychon Bull Rev 2001;8(2):244-61.

[48] Paramei GV. Color Perception and Environmentally Based Impairments. Encyclopedia Color Sci Technol 2013. https://doi.org/10.1007/978-3-642-27851871-5. Springer Science + Business Media New York.

[49] Zuckerman M. Psychobiology of Personality. Cambridge University Press; 1991 and 2005.

[50] Schloss KB, Nelson R, Parker L, et al. Seasonal Variations in Color Preference. Cogn Sci 2017;41:1589-612.

[51] Schloss KB, Heck IA. Seasonal changes in color preferences are linked to variations in environmental colors: a longitudinal study of fall. i-Perception 2017:1-19.

[52] Strauss ED, Schloss KB, Palmer SE. Color preferences change after experience with liked/disliked colored objects. Psychon Bull Rev. 2013;20:935-43.

[53] Schloss KB, Palmer SE. An ecological framework for temporal and individual dif ferences in color preferences. Vision Res 2017;141:95-108.

[54] Duan Y, Rhodes PA, Cheung V. The influence of color on impulsiveness and arousal : Part 2- Chroma. Color Res Appl. 2018;43:405-14.

[55] Curwen C. Music-colour synaesthesia: Concept, context and qualia. Conscious Cogn 2018;61:94-106.

[56] Cohen SB, Wyke MA, Binnie C. Hearing words and seeing colours: an experimental investigation of a case of synaesthesia. Perception 1987;16:761-7. 